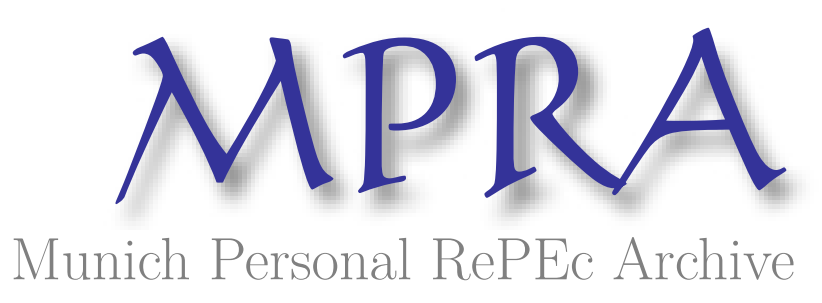

\title{
Bang for Your Buck: STI Risk and Pregnancy Risk as Sources of the Price Premium for Unprotected Sex
}

\author{
Manda, Constantine
}

Twaweza

6 December 2013

Online at https://mpra.ub.uni-muenchen.de/52864/

MPRA Paper No. 52864, posted 13 Jan 2014 13:47 UTC 


\title{
Bang for Your Buck: STI Risk and Pregnancy Risk as Sources of the Price Premium for Unprotected Sex
}

\author{
Constantine Manda *
}

December 6, 2013

\begin{abstract}
Sex workers receive a price premium for unprotected sex. Research has inferred that the source of this premium is a compensating differential for STI risk. I introduce a compensating differential for pregnancy risk as a novel source through a simple model that incorporates both STI risk and pregnancy risk. I empirically test this using a rich panel dataset of 19,041 sexual transactions by 192 sex workers in Busia, Kenya collected during 2005 and 2006. I run sex worker-fixed effects regressions and find that compensating differentials for STI risk and pregnancy risk are sources of the price premium for unprotected sex. The price premium for pregnancy risk is USD 10, and USD 2 for STI risk (24 percent of average price). I also test for clients' disutility for condoms, another competing theory, and find that it is not a statistically significant source of the premium. Identifying and estimating sources of the price premium for unprotected sex will allow policymakers to implement interventions that will reduce both the supply and the demand for unprotected sex.
\end{abstract}

JEL Codes: O12, I10, J30

*I would like to thank Angela Ambroz, Max Bode, Ruth Carlitz, Lauren Falcao, Willa Friedman, James Habyarimana, Stuti Khemani, Erin Litzow, Youdi Schipper, Munshi Sulaiman, Tom Traill, and participants at the CEGA-Twaweza Symposium for useful comments and discussion on earlier drafts of the paper. All errors remain my own. Experimental Interventions, Twaweza, 127 Mafinga Road, Dar es Salaam, Tanzania. E-mail: cmanda@twaweza.org. Telephone: +255713762675. 


\section{Introduction}

Sex workers receive a price premium each time they have unprotected sex. This price premium has been documented in India (Rao et al. 2003), in Mexico (Gertler et al. 2005), in Kenya (Robinson and Yeh 2011), in Congo (Ntumbanzondo et al. 2006), in Chicago (Levitt and Venkatesh 2007) and, most recently, in Ecuador (Arunachalam and Shah 2013). Throughout this literature, however, with the exception of Arunachalam and Shah (2013), researchers have assumed that this premium reflects a compensating differential for STI risk. This inference is made because the price for unprotected sex increases with STI prevalence. Specifically, Arunachalam and Shah (2013) find that a 1 percentage increase in STI prevalence increases the price premium by 33 percentage points. They also find that the anal sex premium is larger than the vaginal sex premium, as do Robinson and Yeh (2011). STIs can be quite costly because as Oster (2005) shows, non-HIV/AIDS STI transmission can be the key factor in HIV/AIDS transmission.

In this paper, I introduce a novel source of the price premium that has gone unexplored in the literature. I argue that another significant source of the price premium is a compensating differential for pregnancy risk. I chart this course because the literature has so far ignored the fact that condoms prevent both STIs and pregnancy. Therefore, looking at the differential prices clients pay for unprotected sex will capture not only sex workers' compensating differential for STI risk but also pregnancy risk. Using a rich dataset from Robinson and Yeh (2011), I test to see whether a compensating differential for pregnancy risk is another source of the price premium for unprotected sex. I also test the compensating differential for STI risk independently and controlling for the possibility of pregnancy risk. For completeness, I also test whether clients' disutility for condoms explains the price premium for unprotected sex. I test for clients' disutility for condoms because the literature also suggests that regardless of sex workers' risk aversion to STIs, a price premium for unprotected sex will still be observed because of 
sex workers' ability to charge clients more because of their disutility for condom use (Arunachalam and Shah 2013). Rao et al. (2003) argues that the price premium for unprotected sex stems from clients' unwillingness to use condoms. Gertler et al. (2005) model the price premium as the result of clients' willingness to pay for and sex workers' willingness to accept unprotected sex, and find that attractive sex workers get about twice the premium for unprotected sex, a measure of bargaining power. The unique contribution of this paper to the literature is the introduction of pregnancy risk as a source of the price premium; employment of innovative techniques to directly measure pregnancy risk using probabilities of pregnancy; and of course the evaluation of all the competing theories of the source of the price premium for unprotected sex.

In testing for the sources of the price premium for unprotected sex, I use robust measures of STI risk, pregnancy risk, and clients' disutility for condoms. ${ }^{1}$ To measure STI risk, I interact two variables. The first is a dummy variable equal to one for each sexual transaction that occurred without a condom. This first variable allows me to identify the price premium for unprotected sex. The second is a dummy variable equal to one for each sexual transaction that occurred with a client who the sex worker viewed as being at high risk of having HIV/AIDS. This second variable allows me to identify how much risky clients get charged by sex workers during sexual transactions. Together, the interaction of these two variables reflect my measure of the price premium for unprotected sex due to STI risk.

To measure pregnancy risk I interact three variables. The first is a dummy variable equal to one for each sexual transaction that occurred without a condom. This first variable allows me to identify the price premium for unprotected sex. The second is a dummy variable equal to one for each sexual transaction that occurred with a sex worker who is not on birth control. This second variable allows me to identify, for sex workers who are not on birth control, how much they charge for sexual transactions.

\footnotetext{
${ }^{1}$ Further details of all these measures are in Section 3.2.
} 
The third is a variable equal to the direct probabilities of pregnancy for each sex worker. This third variable reflects a direct measure of pregnancy risk and together, these three variables allow me identify, for each unprotected sexual transaction, how much a sex worker charged a client during days when her chances of getting pregnant were nonnegligibly above zero.

To measure clients' disutility for condoms, I interact two variables. The first is a dummy variable equal to one for each sexual transaction that occurred without a condom. This first variable allows me to identify the price premium for unprotected sex. The second is a dummy variable equal to one for each sexual transaction that occurred with a client who has unprotected sex more or much more than the average client. This second variable reflects clients' disutility for condoms. Together, these two variables allow me to identify for each unprotected sexual transaction, how much a client with a disutility for condoms pay.

Using all these measures, I run sex worker-fixed effects regressions and find that while a compensating differential for STI risk remains a source of the price premium for unprotected sex, but I also find that a compensating differential for pregnancy risk is another source of the price premium for unprotected sex. In fact, the relationship between pregnancy risk and the price premium for unprotected sex is both statistically and economically stronger than that with STI risk. The price premium for pregnancy risk is USD $10^{2}$, while the price premium for STI risk is USD 2 or 24 percent of average price, but only a fifth of the compensating differential for pregnancy risk. Clients' disutility for condoms has a negative effect on price and is not statistically signficant and so I reject clients' disutility for condoms as a source of the price premium for unprotected sex.

Resolving arguments about the competing sources of the price premium will allow policy makers and health practitioners to better target health interventions and miti-

\footnotetext{
${ }^{2}$ Robinson and Yeh (2011) report that the Kenyan shilling-US dollar exchange rate during sampling was $70 \mathrm{Ksh}$ to the dollar. I use this exchange rate to calculate dollar values throughout this paper to get a sense of these premia in US dollars.
} 
gate the spread of HIV/AIDS. This is particularly important because sex workers have HIV prevalence rates that are higher than other groups in the population and are thus significant drivers of HIV/AIDS epidemics across many countries. Globally, sex workers experience higher rates of HIV infection than in most other population groups (UNAIDS 2009). ${ }^{3}$ In places where STI risk is minimal then pregnancy risk becomes more salient. This is important because a condom-promotion campaign for instance will have little impact on reducing the incentives for sex workers to supply unprotected sex. A better campaign would be to increase access to birth controls that will reduce sex workers' pregnancy risk and thus reduce the price premium for unprotected sex, which in turn reduces incentives to supply unprotected sex, both at the intensive margin (a sex worker reducing the amount of unprotected sex) and the extensive margin (a sex worker exiting the market for sex).

Section 2 provides motivation and a simple theory as to why compensating differentials for STI risk and pregnancy risk are sources of the price premium for unprotected sex. Section 3 presents the data. The remaining sections introduce the empirical specifications and presents results (Section 4), while the penultimate section presents robustness checks and limitations of my analysis (Section 5), and the final section concludes the paper (Section 6).

\section{Motivation and Theory}

\section{$2.1 \quad$ STI Risk}

Although having unprotected sex increases sex workers' risk of STI infection and we should observe them reducing risky sexual behavior (Posner 1992), the price premium for unprotected sex acts to incentivize sex workers towards risky sexual behavior. In an attempt to capture this premium, sex workers are incentivized to instead increase risky sexual behavior. Sex workers also use the price premium to smooth consumption during

\footnotetext{
${ }^{3}$ See Figure in the Appendix that uses data from UNAIDS (2010) showing a linear relationship between HIV prevalence among sex workers and the general population.
} 
idiosyncratic health shocks (Robinson and Yeh 2011). Arunachalam and Shah (2013) provide the most compelling and rigorous evaluation of the compensating differential for STI risk as a source of the price premium for unprotected sex. They introduce a simple theoretical framework than incorporates clients' disutility for condoms as well as sex workers' risk aversion to STI transmission. In this paper, I build on Arunachalam and Shah (2013) by including STI risk in the theoretical framework along with pregnancy risk. Before I introduce the simple model, I will motivate the discussion on why pregnancy risk is also relevant for sex workers.

\subsection{Pregnancy Risk}

Although Arunachalam and Shah (2013) provide rigorous evidence as to why a compensating differential for STI risk is a source of the price premium for unprotected sex, they also find that the price premium for unprotected sex is observed in places with zero STI prevalence. Since condoms exclude the possibility of STI infection as well as pregnancy, the inference that unprotected sex is transacted at a relatively higher price than protected sex as compensation for increased STI risk is far from robust. To resolve this issue, any empirical test of the theory for the compensating differential for STI risk must exclude the possibility of other costs which are also prevented through condom use and which sex workers might potentially wish to avoid, such as pregnancy.

Pregnancy introduces several costs to the sex worker including (1) the direct costs of child-rearing, which are non-negative and non-trivial ${ }^{4}$; (2) lost wages during the latter stages of pregnancy and early stages of the child's infancy when the mother's time is almost exclusively used caring for the infant and she is unable to work for wages; and (3) if the sex worker decides to abort, costs of abortion including monetary costs and any health complications that occur as a result of the procedure, both physiological as well

\footnotetext{
${ }^{4}$ Important inputs in the rearing of children include food and housing at the most basic level and education at a much higher order level all of which are non-trivially above zero.
} 
as psychic costs. ${ }^{5}$ The profit maximizing sex worker would thus engage in unprotected sex if and only if the price premium for unprotected sex is greater than the marginal cost to unprotected sex, i.e. STI risk and pregnancy risk.

\subsection{STI Risk and Pregnancy Risk}

To fix ideas, I present a simple model that incorporates both STI risk and pregnancy risk. I argue more formally and let $P_{1}$ be the price received by a sex worker for unprotected sex in the sex market or the price premium; $P_{2}$ be the price received by a sex worker for protected sex in the sex market; $\mathrm{Q}$ be sexual transactions by the sex worker in the sex market; $\mathrm{G}$ and $\mathrm{S}$ be the probability of getting pregnant and contracting an STI, respectively (where of course $(0 \leq G \leq 1$ and $0 \leq S \leq 1)$. Let $C_{g}$ be all the costs of pregnancy, including costs of rearing a child from pregnancy to maturity into adulthood and independence or any abortion costs, while $C_{s}$ be all the costs of STI transmission such as direct health costs and lost wages during symptomatic periods. As such, if the sex worker chooses to supply unprotected sex, her expected pay off would be;

$$
P_{1} Q-G C_{g}-S C_{s}
$$

On the other hand, if the CSW chooses to supply protected sex, her expected pay

\footnotetext{
${ }^{5}$ Besides these costs, an additional cost might be reduced marriage prospects. Siow (1998) and Edlund and Korn (2002) assume that men prefer to marry women who have no children implying that children might also potentially reduce marriage prospects. Becker (1993) argues that children are seen as capital investment in marriage, and thus the prospect of divorce lowers the accumulation of children and also shows that empirically, divorced women with children remarry more slowly than divorced men. Weitzman and Dixon (1979) argue that young children raise the cost of searching for another mate and reduce the net resources of these mothers. Although all these should push us to believe that sex work lowers marriage prospects, sex workers in our dataset however, say that sex work has increased their marriage prospects. Although Robinson and Yeh (2011) suggest that sex work might affect marriage prospects on the intensive (partner quality) rather than the extensive (finding a partner) margin, I exclude this possible cost of marriage prospects so to not detract from the general point that pregnancy and its products are costly to sex workers.
} 
off would be;

$$
P_{2} Q-G C_{g}-S C_{s}
$$

where in this case $\mathrm{G}$ and $\mathrm{S}$ are both zero ${ }^{6}$ and so that her expected pay off to supplying protected sex reduces to;

$$
P_{2} Q
$$

Her decision rule is thus very simply to supply unprotected sex if and only if (1) is greater than (2), but to simplify, I let $Q$ equal to 1 , so that the sex worker is making this decision each time she engages in transactional sex or;

$$
P_{1}-G C_{g}-S C_{s}>P_{2}
$$

and I can thus bring $G C_{g}$ and $S C_{s}$ to the other side, we get;

$$
P_{1}>P_{2}+G C_{g}+S C_{s}
$$

This implies that the profit maximizing sex worker will supply unprotected sex in the sex market if and only if the price received for unprotected sex exceeds the price received for protected sex in the sex market and/or exceeds the sum of the probabilities of getting pregnant and getting STIs, the costs of pregnancy and STI transmission.

In their modeling, Arunachalam and Shah (2013) propose that it is not possible to

\footnotetext{
${ }^{6}$ Many studies have showed that condoms are highly effective at preventing, not only STI transmission, but also pregnancy. Davis and Weller (1999) for instance document condom efficacy in relation to HIV transmission and pregnancy. They find that the likelihood of pregnancy after protected sexual intercourse is as low as 0.026 and a condom's effectiveness at preventing HIV transmission is estimated to be as high as 96 percent. This simplifying assumption allows me to focus on just the effects of STI risk and pregnancy risk whenever a condom is not used, but is not an impossible scenario.
} 
unambiguously sign $P_{1}-P_{2}$ whenever STI risk equals zero. In essence, they are not able to distinguish between $G C_{g}+S C_{s}>0$ and $S C_{s}>0$. I show that their assumption that if $S C_{s}=0$ then one cannot sign the price differential between unprotected and protected sex is incomplete. Notice that their argument is that when $P_{1}>P_{2}+G C_{g}+S C_{s}$, as in my framework, and we rearrange to make $P_{1}-P_{2}>G C_{g}+S C_{s}$ and let $S C_{s}=0$, then it is impossible to sign $P_{1}-P_{2}$ but in my framework this price differential is greater than $G C_{g}$ and if we take the existence of the price premium as given, then $G C_{g}>0$. This means that since $G \neq 0$ (lower bound for any probability is zero) then $C_{g} \neq 0$ and in fact must be greater than zero because there cannot be returns to pregnancy, at least not immediately, that will factor into a sex worker's decision to have protected or unprotected sex. Notice also then that if $G C_{g}>0$ and $C_{g}>0$ then $G>0$.

Given all of this then I can formally propose the following.

\subsection{Proposition}

If $S C_{s}=0$ and $P_{1}-P_{2}>0$ then $G C_{g}>0 .{ }^{7}$ In other words, if STI risk is zero and there exists a price premium for unprotected sex, then it must be that a compensating differential for pregnancy risk is the source of the price premium for unprotected sex.

\subsection{Implications}

Given that condoms prevent both STIs and pregnancy, if we observe sex being transacted at a higher price when no condom is used and STI prevalence is zero, then it must be that the compensating differential for pregnancy risk is a source of the price premium for unprotected sex. The major insight in this paper is that what Arunachalam and Shah (2013) really observe is $P_{1}-P_{2}>G C_{g}+S C_{s}>0$ but they assume they are observing $P_{1}-P_{2}>S C_{s}>0$, failing to distinguish the two structural equations. I will show in this paper that the observed price premium for unprotected sex sits within the

\footnotetext{
${ }^{7}$ All proofs are presented in the Appendix.
} 
first structural equation rather than the second. Sections 3 and 4 introduce the data and the empirical specifications.

\section{Data and Summary Statistics}

\subsection{Data}

The dataset is from Robinson and Yeh $(2011)^{8}$ and includes background information and self-reported information by 192 sex workers reporting on 19,041 sexual transactions in 12,536 sex worker days. A random sample of 248 women were selected to be a part of the study from 1,205 women identified. Of these 248 women, only 192 women had complete and usable data. Of these 56 that did not constitute the final sample, 7 refused to participate at all, and the remaining 49 either did not complete the study or had unusable reported data. Robinson and Yeh (2011) report that these 49 attrited women are not statistically different along most background characteristics as those who remained in the study. Data collection occurred between October 2005 and October 2006. A baseline survey collected background information on the women, and all women were asked to keep and record sexual transactions through provided diaries. The women were compensated with paid cash for keeping these diaries. The women were asked to provide detailed information about the sexual transactions with clients (up to a maximum of three transactions per day). To avoid losing illiterate women in the sample, efforts were made to help these women fill in the diaries, however literacy in the sample was relatively high with 95 percent and 88 percent of sampled women being able to read and write Kiswahili, respectively. ${ }^{9}$

\footnotetext{
${ }^{8}$ More details on this dataset can be found on pages 39-43 from Robinson and Yeh (2011).

${ }^{9}$ See Table 7.1.
} 


\subsection{Measuring Pregnancy Risk, STI Risk, and Clients' Disutility for Condoms}

In order to measure pregnancy risk, STI risk, and clients' disutility for condoms, I interacted several variables from the Robinson and Yeh (2011) dataset.

\subsubsection{STI Risk}

To measure STI risk, I interact two variables. The first is a dummy variable equal to one for each sexual transaction that occurred without a condom. This first variable allows me to identify the price premium for unprotected sex. The second is a dummy variable equal to one for each sexual transaction that occurred with a client who the sex worker viewed as being at high risk of having HIV/AIDS. This second variable allows me to identify how much risky clients get charged by sex workers during sexual transactions. Together, the interaction of these two variables reflect my measure of the price premium for unprotected sex due to STI risk.

\subsubsection{Pregnancy Risk}

To measure pregnancy risk I interact three variables. The first is a dummy variable equal to one for each sexual transaction that occurred without a condom. This first variable allows me to identify the price premium for unprotected sex. The second is a dummy variable equal to one for each sexual transaction that occurred with a sex worker who is not on birth control. This second variable allows me to identify, for sex workers who are not on birth control, how much they charge for sexual transactions. The third is a variable equal to the direct probabilities of pregnancy for each sex worker. I use estimated probabilities of pregnancy from Wilcox et al. (2001) and Wilcox et al. (1995). Wilcox et al. (2001) calculate estimated mean probabilities of clinical pregnancy for each day of a woman's menstrual cycle ${ }^{10}$ while Wilcox et al. $(1995$, p. 1519) provide

\footnotetext{
${ }^{10}$ Table 1 on page 213 of Wilcox et al. (2001) presents these estimates.
} 
probabilities of pregnancy for a woman who has unprotected sexual intercourse everyday (0.37), every other day (0.33), and once per week (0.15).

Before assigning probabilities of pregnancy, however, I first must have information on the exact day a sex worker is in her menstrual cycle. Ideally, the Robinson and Yeh (2011) dataset would have collected information on this by either asking the women exactly what day they are in their menstrual cycle or by asking a simpler question on how many days have passed since the last day of their menstruation. This information would allow me to know exactly, for each sexual transaction, the day of the menstrual cycle a particular sex worker is in. However, the Robinson and Yeh (2011) dataset does not have information that allows me to know what day a particular sex worker is in her menstrual cycle. It does, on the other hand, have information on, for each sexual transaction, whether the sex worker was menstruating the day before or currently menstruating for the day of the recorded sexual transactions. These two variables allow me to know with certainty, for each sexual transaction, when a sex worker is on the first to fifth day of her menstrual cycle.

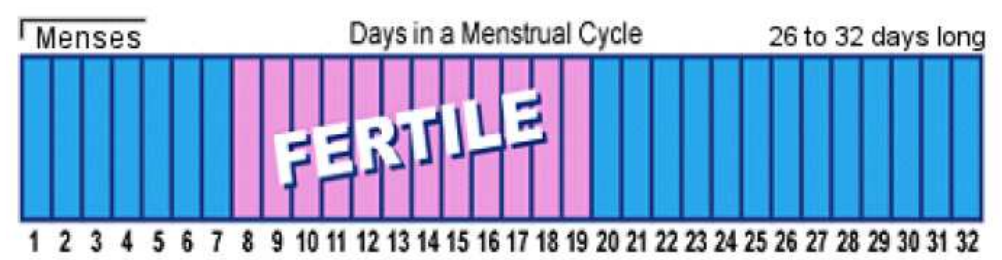

Figure 1: Menstrual Cycle of the Average Woman.

Source: http: //www.cyclebeads.com

Specifically, if the sex worker reports not having menstruated the day before, and menstruating the day of the recorded sexual transactions, then she is on the first day of her "menses". If the sex worker reports having menstruated the day before, but not menstruating the day of the recorded sexual transactions, then she is on the fifth day of 
her menstrual cycle. If the sex worker reports menstruating the day before and the day of the recorded sexual transactions, then she is either on the second, third, or fourth day of her menstrual cycle. The data does not allow me to distinguish exactly which of these days is possible, so in assigning probabilities of pregnancy for these days, I average estimated probabilities for each of these days and assign this average whenever a sex worker reports menstruating the day before and the day of the recorded sexual transactions.

Even more uncertain is when a sex worker reports not menstruating the day before and not menstruating the day of the recorded sexual transactions. The sex worker could be in any one of the remaining twenty-seven days between the sixth and the thirty-second day of her menstrual cycle. ${ }^{11}$ To try and reduce this problem, I estimate the probability that the sex worker is on the days within her fertile window period. A woman's fertile window $^{12}$ is during the twelve days between the eighth and the nineteenth day, inclusive, of her menstrual cycle. Given that the data allows me to know when a sex worker is on the days between the first and the fifth day, inclusive, of her menstrual cycle, I subtract these first five days from the total days of her menstrual cycle to find the total number of possible days that a sex worker might be on if she reports not menstruating the day before and not menstruating the day of the recorded sexual transactions. This subtraction deduces to a total of twenty-seven possible days (thirty-two minus five) that a sex worker might be on if she reports not menstruating the day before and not menstruating the day of the recorded sexual transactions. So the probability that a sex worker is on days that are within her fertile window period is twelve over twenty-seven or 0.4444444 .

\footnotetext{
${ }^{11}$ Although a typical menstrual cycle lasts between twenty-six and thirty-two days, I assume sex workers in the sample have thirty-two day-menstrual cycles so that my pregnancy probabilities constitute lower bound and thus conservative estimates of a sex worker's chances of getting pregnant. This allows for any identification of pregnancy risk's effect on the price for unprotected sex to be as conservative as possible.

${ }^{12}$ Please note that this fertile window period incorporates a woman's ovulation cycle and sperm life within a woman's body and that around 80 percent of women fall within this fertile window because they typically have 26-32 day menstrual cycles (University 2013).
} 
After estimating the exact menstrual day for each sex worker during each day of recorded sexual transactions, I assign probabilities for exact days of the menstrual cycle, and multiply probabilities of pregnancy with probability of the sex worker being in a particular menstrual day including most importantly, days that fall within her fertile window period. For days that fall within a sex worker's fertile window period, I use Wilcox et al. (1995)'s probability of clinical pregnancy for a woman who has unprotected sexual intercourse every other day, which is $0.33 .{ }^{13} \mathrm{I}$ multiply this probability with 0.4444444 , which is the probability that a sex worker is on a day within her fertile window period and get 0.14666666666 , which I assign to a sex worker who reports not menstruating the day before and not menstruating the day of the recorded sexual transactions. ${ }^{14}$

In summary, this third variable is equal to zero if a sex worker is on the first day of her menstrual cycle and equal to $0.004^{15}$ if a sex worker is on the fifth day of her menstrual cycle. Recall that because I do not know with absolute certainty whether a sex worker is on the second, third, or fourth day of her menstrual cycle, I average the probabilitites for each of these days from the Wilcox et al. (2001) data. Those estimates are probabilities of pregnancy of zero for the second day; 0.001 for the third day; and 0.002 for the fourth

\footnotetext{
${ }^{13}$ I use this probability because about 81 percent of sex workers in the sample had sexual intercourse each day and so this is a lower bound estimate of the chances of these women getting pregnant given their relatively high sexual activities. More importantly, although frequent sexual intercourse affects the potency of sperm (MacLeod and Gold 1953; Freund 1962; Poland et al. 1985), these sexual transactions did not necessarily occur with the same clients. In fact, only 17 percent of transactions, on average, in the dataset occurred with regular clients, while on the other hand, over 64 percent of transactions, on average, occurred with casual clients. It is also important to note that Dunson et al. (1999), in re-evaluating Wilcox et al. (1995)'s estimates, revises those estimates to as high as 0.42. Both these points are important to keep in mind because the probability of pregnancy I use here for these women (sex workers) constitutes a conservative estimate of their actual probabilities of pregnancy.

${ }^{14}$ Although the probability of pregnancy is dependent on the menstrual day that a woman is on, this particular probability covers the probability of pregnancy for a woman who has sexual intercourse every other day, regardless of her menstrual days, and thus independent. This allows me to multiply the two probabilities as per simple probability theory. Moreover, using the probability of pregnancy for a woman who has sexual intercourse everyday (0.37) would have been even more appropriate, but this would have provided an upper bound estimate and for the purposes of this paper, might provide overestimated effects of pregnancy risk on the price for unprotected sex.

${ }^{15}$ Table 1 on page 213 of Wilcox et al. (2001) presents these day-specific probability of pregnancy estimates.
} 
day of a sex worker's menstrual cycle. ${ }^{16}$ The average of these three estimates is thus 0.001, which is what I use whenever a sex worker reports having menstruated the day before and menstruating the day of the recorded sexual transactions. Finally, this third variable is equal to 0.14666666666 for sex workers that report not having menstruated the day before or the day of the recorded transactions. ${ }^{17}$ In other words, for sex workers that are not in the first, second, third, fourth or fifth days of their menstrual cycles.

\subsubsection{Clients' Disutility for Condoms}

To measure clients' disutility for condoms, I interact two variables. The first is a dummy variable equal to one for each sexual transaction that occurred without a condom. This first variable allows me to identify the price premium for unprotected sex. The second is a dummy variable equal to one for each sexual transaction that occurred with a client who has unprotected sex more or much more than the average client. This second variable reflects clients' disutility for condoms. Together, these two variables allow me to identify for each unprotected sexual transaction, how much a client with a disutility for condoms pay.

\subsection{Summary Statistics}

Summary statistics are presented in Tables 1-3 in the Appendix. The average sex worker in the sample is 28 years old, started sex work when she was around 19 years old, has 2 children, and has completed over nine grade years of education. ${ }^{18}$ Forty-four percent of sex workers in the sample have never been married, while twenty-three and twenty percent of sex workers in the sample have been widowed or divorced, respectively.

\footnotetext{
${ }^{16}$ Ibid.

${ }^{17}$ Notice here that by collapsing the twenty-seven days between days 7 and 32 , inclusive, I lose a lot of pregnancy risk variation. So my pregnancy risk measure is imprecise and quite conservative. Any effect I find is thus convincing evidence of a compensating differential for pregnancy risk, given the conservative and noisy measure of pregnancy risk.

${ }^{18}$ The education level of the sex workers in the sample is similar to that of the average Kenyan woman (Robinson and Yeh 2011).
} 
Ninety percent of the sampled women come from the Luo and Luhya tribes.

Table 7.1 here.

The women in the sample are well informed about the risks related to HIV/AIDS, as demonstrated by the fact that the average woman in the sample scored 94 out of 100 on a test of HIV knowledge. The test evaluated knowledge on HIV transmission, risk reduction methods, and misconceptions surrounding HIV/AIDS. Women in the sample earn more money from sex work than from other activities. The average woman in the sample earns 851 Ksh (USD 12) a day from over 7 hours of sex work, for an hourly wage rate of about $152 \mathrm{Ksh}$ (USD 2). Alternatively, the average woman earns just $106 \mathrm{Ksh}$ (USD 1.5) per day from other work over an 8 hour day, for a daily wage rate of about $41 \mathrm{Ksh}$ (USD 0.6). Sex workers in this sample are similar to other sex worker samples from other studies in this regard because the average sex worker typically earns more than a similar woman with similar demographics in the general population (Edlund and Korn 2002; Gertler et al. 2005; Arunachalam and Shah 2013).

Table 7.2 here.

The data also provides very detailed information on all the 3,656 clients. Nine percent of clients are considered poor ${ }^{19}$ and about twenty-seven percent are government employees. Nineteen percent work as truck drivers and another nineteen percent businessmen. Forty-nine percent are from the Luhya and Luo tribes. Fourteen percent are from the Kikuyu tribe, while six percent and four percent are Somalis and Ugandans, respectively. Sixty-two percent and fifty-four percent of clients are considered clean and handsome, respectively. A quarter of clients are uncircumcised, and forty-six percent are considered at high risk of HIV/AIDS. Forty-five percent of clients have some disutility for condoms.

\footnotetext{
${ }^{19}$ Details on what constitutes poor can be found in Robinson and Yeh (2011).
} 


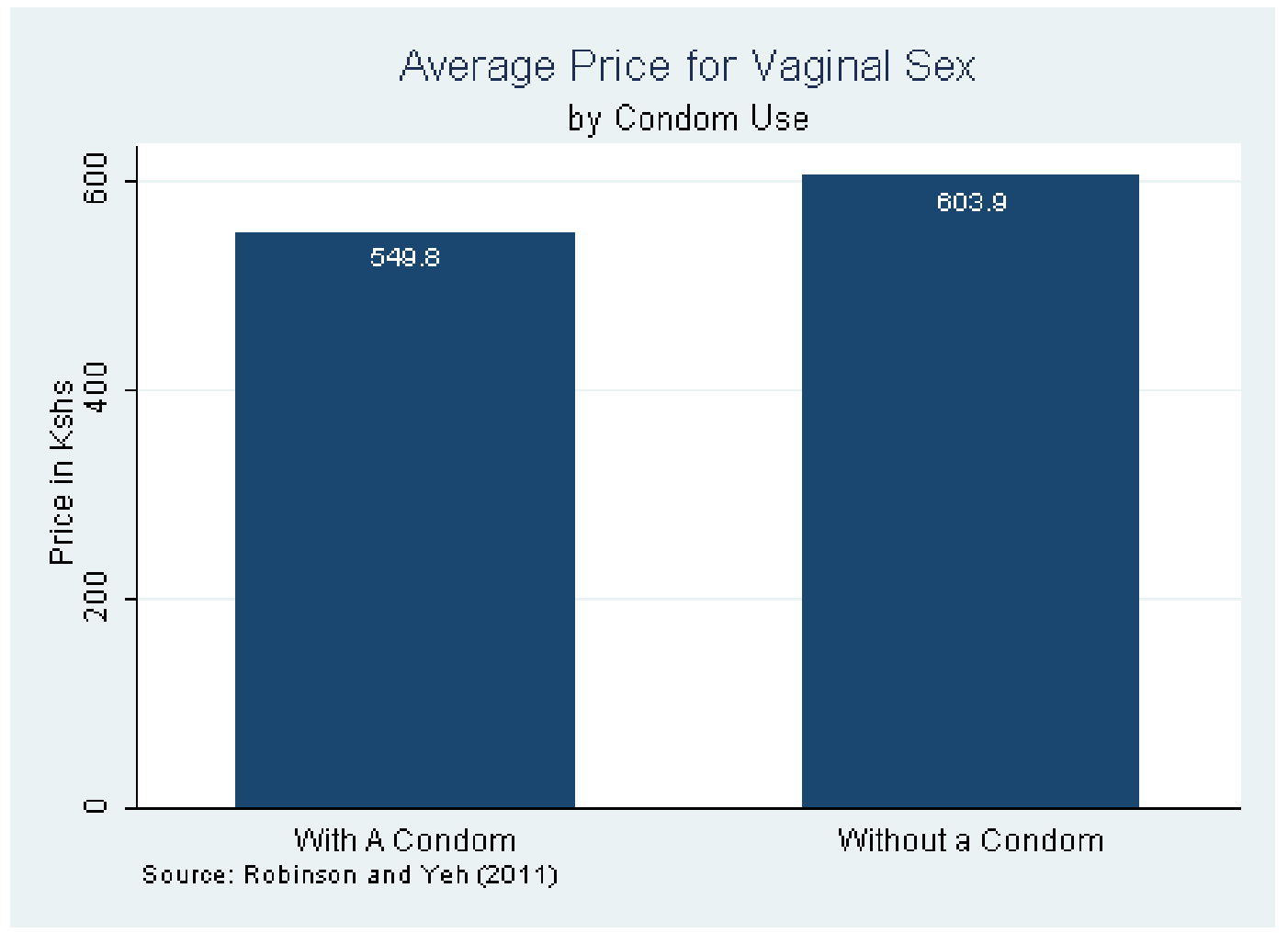

Figure 2: Price Premium for Unprotected Sex.

Eight percent of sex workers reported having vaginal sex without a condom. Three percent of sex workers report having some STI and an equal percentage report having unprotected vaginal sex with a client at high risk of HIV/AIDS. Sixty percent of sex workers are on birth control and nine percent and eight percent of sex workers were menstruating yesterday and today, respectively. The average woman received $510 \mathrm{Ksh}$ (USD 7.3) for each sexual transaction. Figure 3.3 shows that the average price for each unprotected vaginal sexual transaction is $604 \mathrm{Ksh}$ (USD 8.6), while each vaginal sexual transaction with a condom is 550 Ksh (USD 7.9), providing suggestive evidence that there is a price premium for unprotected sex consistent with the literature.

Table 7.3 here. 


\section{Empirical Specifications and Results}

\subsection{Specification}

To test the competing theories of sources of the price premium, I estimate four main fixed effects regression models. Sex worker- and client-specific controls are included in the complete specifications, with day and month dummies. ${ }^{20}$ The first three models regress the price for transactional sex in Kenyan shillings separately on STI risk (1), pregnancy risk (2), and clients' disutility for condoms (3). The equations are as follows;

$$
\begin{aligned}
P_{i r t}= & \beta_{0}+\beta_{1} N C+\beta_{2} R L+\beta_{3}(N C \times R L)+\sum_{s=1}^{S} \beta^{s} \gamma_{i r t}^{s}+\sum_{c=1}^{C} \beta^{c} \omega_{i r t}^{c}+ \\
& \alpha_{i}+\tau_{t}+\epsilon_{i r t} \\
P_{i r t}= & \beta_{0}+\beta_{1} N C+\beta_{2} P P+\beta_{3}(P P \times N B)+\beta_{4}(N C \times P P \times N B)+ \\
& \sum_{s=1}^{S} \beta^{s} \gamma_{i r t}^{s}+\sum_{c=1}^{C} \beta^{c} \omega_{i r t}^{c}+\alpha_{i}+\tau_{t}+\epsilon_{i r t} \\
P_{i r t}= & \beta_{0}+\beta_{1} N C+\beta_{2} D C+\beta_{3}(D C \times N C)+\sum_{s=1}^{S} \beta^{s} \gamma_{i r t}^{s}+\sum_{c=1}^{C} \beta^{c} \omega_{i r t}^{c}+ \\
\alpha_{i}+ & \tau_{t}+\epsilon_{i r t}
\end{aligned}
$$

where $N C$ or $N o$ Condom is a dummy variable equal to one when a condom is not used during vaginal sex; $R L$ or Risky Client is a dummy variable equal to one when the sexual transaction occurred with a client whom the sex worker reported as being at

\footnotetext{
${ }^{20}$ I control for sex workers' age, experience, years of education, literacy, tribe, marital status, and number of children. I also control for whether clients are regular, clean, wealthy, handsome, and for their ethnicity. Finally, I include day and month dummies in all specifications.
} 
high risk of HIV/AIDS; and of course $N C \times R L$ is the interaction between the two, and constitutes my main measure of STI risk.

PP or Probability of Pregnancy is the direct measure of clinical pregnancy for each sexual transaction; $N B$ or No Birth Control is a dummy variable equal to one when the sexual transaction occurred with a sex worker who is not on birth control; $P P \times$ $N B$ is the interaction between the Probability of Pregnancy and No Birth Control; and of course $N C \times P P \times N B$ is the interaction between No Condom, the Probability of Pregnancy, and No Birth Control.

Finally, $D C$ or Clients' Disutility for Condoms is a dummy variable equal to one when a sexual transaction occurred with a client who has more or much more unprotected sex than the average client. ${ }^{21}$ Of course, $D C \times N C$ is the interaction between Clients' Disutility for Condoms and No Condom.

In the specifications above, $r$ indexes transactions, for the $i$ th sex worker at the $t$ th date. Please note that $\gamma_{i r t}^{s}$ and $\omega_{i r t}$ are sex worker- and client-controls, respectively, while $\alpha_{i}$ and $\tau_{t}$ represent the sex worker and time fixed effects, respectively. The sex worker fixed effect $\alpha_{i}$ will account for differences across sex workers in attractiveness (bargaining power), fertility, and risk preferences, while $\tau_{t}$ will pick up other time-varying effects, such as day-specific demand changes. ${ }^{22}$ Finally, $\epsilon_{\text {irt }}$ is an idiosyncratic error term. In all specifications standard errors are clustered at the sex worker level. ${ }^{23}$

The first specification (1) tests for STI risk. The coefficient $\beta_{3}$ from specification (1) represents the price of a sexual transaction that occurred without a condom and with a risky client; $\beta_{2}$ represents the price for protected sex with a client who is not risky, while

\footnotetext{
${ }^{21}$ This dummy variable incorporates two dummy variables from the Robinson and Yeh (2011) data. Those two variables are a dummy variable equal to one when a sex worker reports having sex with a client who has more unprotected sex than average client; and a dummy variable when a sex worker reports having sex with a client who has much more unprotected sex than average client.

${ }^{22}$ This fixed effects specification is consistent with the literature. Robinson and Yeh (2011) includes a sex worker fixed effect as well as time dummies, while Arunachalam and Shah (2013) include just a sex worker fixed effect.

${ }^{23}$ Running all the models by clustering standard errors at the sex worker level, to account for the fact that errors are likely correlated for a particular sex worker is consistent with Robinson and Yeh (2011), while Arunachalam and Shah (2013) cluster at the sex worker city location level.
} 
$\beta_{1}$ captures the price paid for unprotected sex with a client who is not risky. Results for this specification are presented in Table 7.4.

The second specification (2) tests for pregnancy risk. The coefficient $\beta_{4}$ from specification (2) represents the price of a sexual transaction that occurred without a condom, with a sex worker who is not on birth control, and interacted with the probability of pregnancy; $\beta_{3}$ represents the price for protected sex with a sex worker who is on birth control, interacted with the probability of pregnancy; $\beta_{2}$ represents the price dependent on the probability of pregnancy, when a condom is used with a sex worker who is on birth control, while $\beta_{1}$ captures the price paid for unprotected sex when there is no pregnancy risk. Results for this specification are presented in Table 7.5.

Finally, the third specification (3) tests for clients' disutility for condoms. The coefficient $\beta_{3}$ from specification (3) represents the price of a sexual transaction that occurred without a condom and with a client who has a disutility for condoms; $\beta_{2}$ represents the price for protected sex with a client who has a disutility for condoms, while $\beta_{1}$ captures the price paid for unprotected sex with a client who does not have a disutility for condoms. Results for this specification are presented in Table 7.6.

If these regression models are properly specified and a relationship between STI risk; pregnancy risk; clients' disutility for condoms; and the price premium for unprotected sex is identified, then $\beta_{3}$ will reflect a compensating differential for STI risk and client's disutility for condoms for specifications (1) and (3), respectively, while $\beta_{4}$ will reflect a compensating differential for pregnancy risk for specification (2).

Finally, in a fourth specification (4) I include STI risk and pregnancy risk. ${ }^{24}$

\footnotetext{
${ }^{24}$ I drop clients' disutility for condoms, because as results will show, clients' disutility for condoms do not drive the price premium for unprotected sex.
} 


$$
\begin{aligned}
P_{i r t}= & \beta_{0}+\beta_{1} N C+\beta_{2} R L+\beta_{3}(N C \times R L)+\beta_{4} P P+\beta_{5}(P P \times N B)+ \\
& \beta_{6}(N C \times P P \times N B)+\sum_{s=1}^{S} \beta^{s} \gamma_{i r t}^{s}+\sum_{c=1}^{C} \beta^{c} \omega_{i r t}^{c}+\alpha_{i}+\tau_{t}+\epsilon_{i r t}
\end{aligned}
$$

Once again if this regression is properly specified and a relationship between STI risk and pregnancy risk and the price premium for unprotected sex is identified, then $\beta_{3}$ will reflect a compensating differential for STI risk and $\beta_{6}$ will reflect a compensating differential for pregnancy risk.

To summarize, the first three models (specifications (1-3)) separately estimate the effects that STI risk, pregnancy risk, and clients' disutility for condoms have on the price for transactional sex, while the fourth model (specification (4)) includes both STI risk and pregnancy risk. This last model evaluates the competing sources against each other and provides robust estimates as to which effect is largest as a source of the price premium for unprotected sex. The second specification (2) answers the proposition from Section 2.4.

\subsection{Results}

Main results from all the specifications are presented in Tables (7.4-7.7). Table 7.4 presents results for the STI risk specification (1). Columns 1-2 include just STI risk, with column 1 run without sex worker and client controls; and column 2 run with all the controls. Columns 3-4 include the full specification, once again with column 3 run without sex worker and client controls; and column 4 run with all the controls.

Figure 4.2, although from raw data, motivates results from Table 7.4. The figure clearly shows that average price for unprotected sex is higher with a risky client than with a non-risky client. In fact, unprotected sex with a risky client is transacted at around 691 Ksh (USD 9.9), while protected sex with a risky client and/or unprotected 
sex with a non-risky client is transacted at around 585 Ksh (USD 8.4).

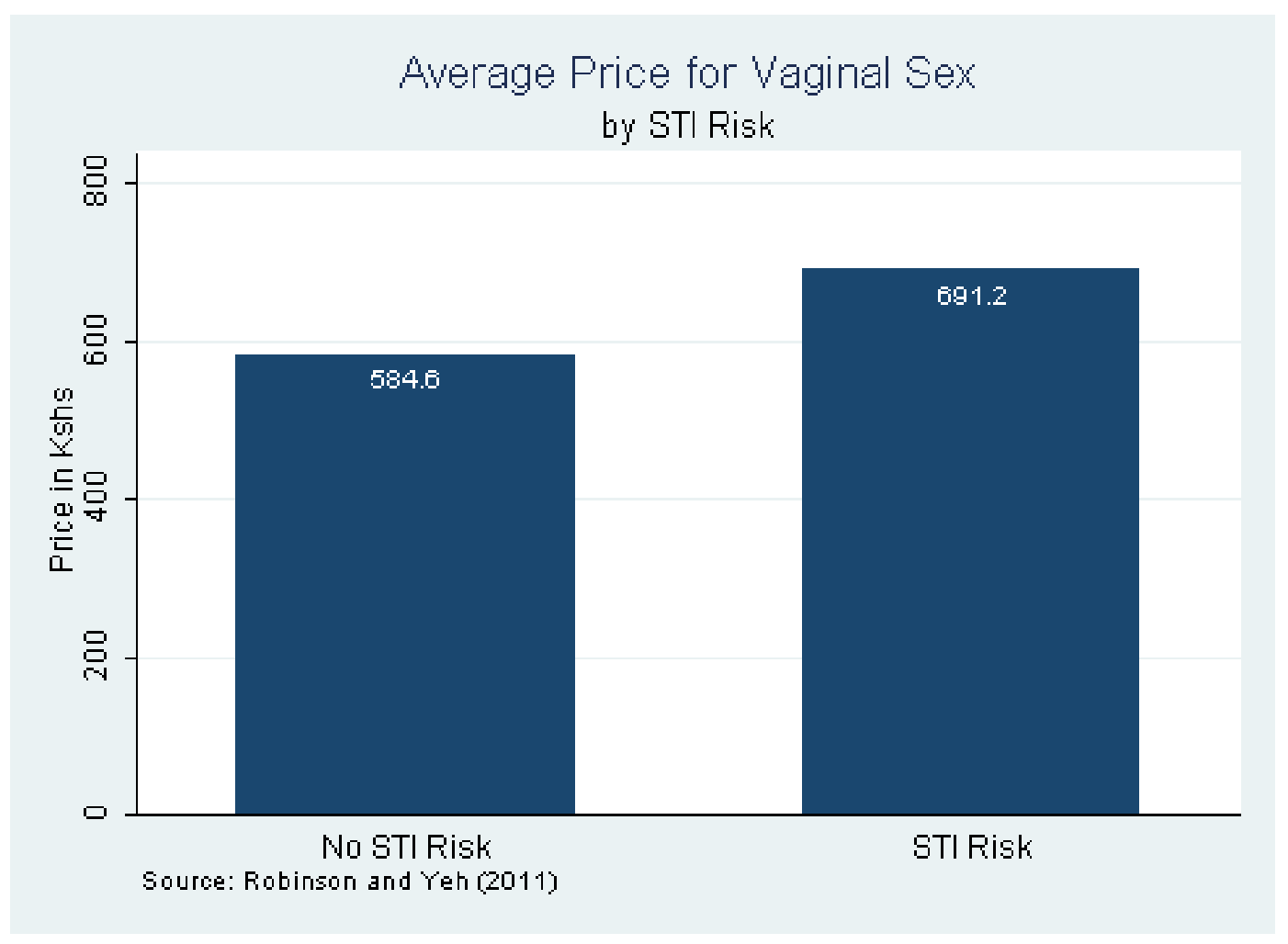

Figure 3: Compesanting Differential for STI Risk.

Specifically, results from Table 7.4 show that a sex worker is compensated $143 \mathrm{Ksh}$ or USD 2 (column 2) for the risk of getting an STI. This coefficient is statistically significant at 5 percent. When I control for risky clients; unprotected sex; sex worker and client characteristics; as well as include time dummies this coefficient remains basically unchanged (column 4) at 143 Ksh (USD 2), but standard errors increase slightly. This coefficient, nevertheless, is still statistically significant at 10 percent.

Figure 4.2, although from raw data, motivates results from Table 7.5. The figure clearly shows that average price for unprotected sex increases with the probability of pregnancy. 


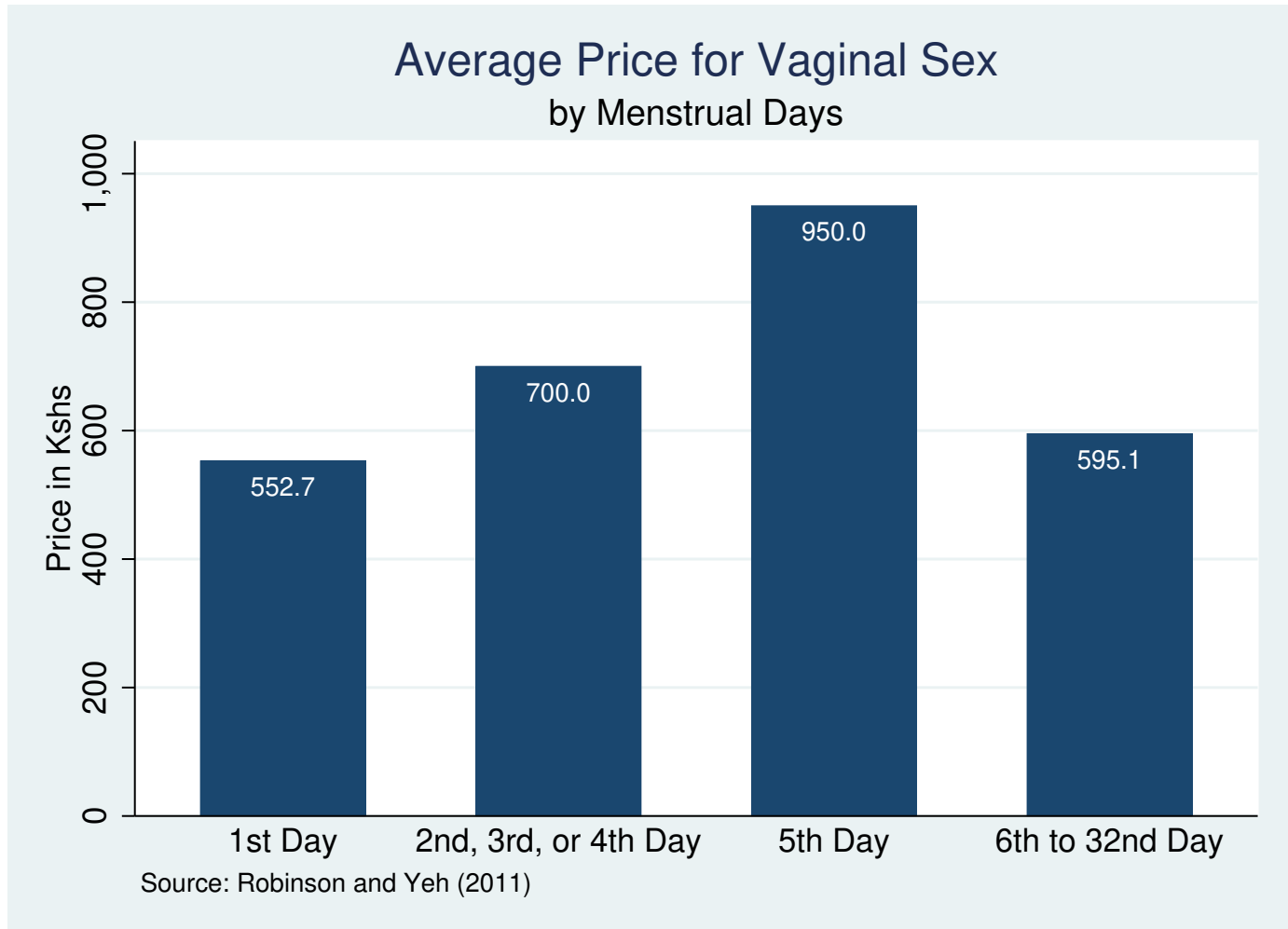

Figure 4: Compesanting Differential for Pregnancy Risk.

Specifically, on the 1st day of the menstrual cycle, when the probability of pregnancy is zero, average price is about $553 \mathrm{Ksh}$ (USD 7.9); $700 \mathrm{Ksh}$ (USD 10) on the 2nd, 3rd, or 4th days of the menstrual cycle, when the probability of pregnancy is $0.001 ; 950 \mathrm{Ksh}$ (USD 13.6) on the 5th day of the menstrual cycle, when the probability of pregnancy is 0.004 . Although the average price drops to $595 \mathrm{Ksh}$ (USD 8.5) for days 6 to 32, note two things:

1. Recall that these average prices are calculated over twenty-seven days in the menstrual cycle collapsing a lot of variation in the probability of pregnancy.

2. The average price for these collapsed probabilities of pregnancy for days 6 to 32 is still higher than the average price for the 1st day of the menstrual cycle. Ideally, 
having exact information of a sex worker's menstrual cycle for each sexual transaction would have allowed me to more precisely identify pregnancy risk's effect on the price premium for unprotected sex.

Nevertheless, results will show that even with this noisy and imprecise measure of pregnancy risk, it still suffices to identify a compensating differential for pregnancy risk.

Table 7.4 here.

Table 7.5 presents results for the pregnancy risk specification (2). Columns 1-2 include just pregnancy risk, with column 1 run without sex worker and client controls; and column 2 run with all the controls. Columns 3-4 include the full specification, once again with column 3 run without sex worker and client controls; and column 4 run with all the controls. Results show that a sex worker is compensated as much as $716 \mathrm{Ksh}$ (USD 10) for the risk of getting pregnant. Notice that this is five times the compensating differential for STI risk and the pregnancy risk coefficient, from column 4 of Table 7.5, is more statistically significant (5 percent versus 10 percent) than the STI risk coefficient from column 4 of Table 7.4.

Table 7.5 here.

Table 7.6 presents results for the clients' disutility for condoms specification (3). Columns 1-2 include just clients' disutility for condoms, with column 1 run without sex worker and client controls; and column 2 run with all the controls. Columns 3-4 include the full specification, once again with column 3 run without sex worker and client controls; and column 4 run with all the controls. Column 1 shows that the price premium for clients' disutility for condoms is about $30 \mathrm{Ksh}$ (0.43 USD), but the coefficient is not statistically significant at 10 percent. Moreover, in columns 2-4, the coefficient remains statistically insignificant and becomes negative. In the full specification (column 4) the coefficient can be interpreted as the price transacted without a condom and with 
a client who has a disutility for condoms occurs at roughly 70 Ksh (USD 1) less than otherwise.

Table 7.4 here.

Finally, Table 7.7 presents results for the fourth specification (4). Columns 1-2 include just STI risk and pregnancy risk, with column 1 run without sex worker and client controls; and column 2 run with all the controls. Columns 3-4 include the full specification, once again with column 3 run without sex worker and client controls; and column 4 run with all the controls. Specifically, columns 3-4 also control for unprotected sex; risky client; probability of pregnancy; and pregnancy risk when a condom is used.

Table 7.7 here.

Column 1 shows that 76 Ksh (USD 1) and 594 (USD 8.5) are compensating differentials for STI risk and pregnancy risk, respectively. However, these coefficients are not statistically significant at 10 percent. Column 3, that includes the full specification except sex worker and client controls, shows that a compensating differential for STI risk increases to $102 \mathrm{Ksh}$ (USD 1.5), while a compensating differential for pregnancy risk also increases to 802 Ksh (USD 11.5). However, the former coefficient (STI Risk) is not statistically significant at 10 percent, while the latter coefficient is statistically significant significant at 10 percent. When I include sex worker and client controls, the coefficient on STI risk becomes 92 Ksh (USD 1.3) and highly statistically insignificant at 10 percent. Alternatively, the coefficient on pregnancy risk jumps to $861 \mathrm{Ksh}$ (USD 12.3), but so too do the standard errors, making the p-value jump to 13 percent, and thus only just statistically insignificant at the 10 percent level.

Although this result is null, I discuss in Section 5, not only why I find this result, but why it does not reject a compensating differential for pregnancy risk. I do reject, however, clients' disutility for condoms as a source of the price premium for unprotected 
sex. Although specifications (1-2) show that a compensating differential for STI risk remains, a compensating differential for pregnancy risk is not only larger, but also more statistically significant. In section 5 that follows, I explore possible threats to internal validity, provide several robustness checks, and discuss limitations of the paper.

\section{$5 \quad$ Robustness and Limitations}

I have presented evidence of compensating differentials for STI risk and pregnancy risk as sources of the price premium for unprotected sex. To explore possible threats, I separately present robustness checks for each of these sources.

\subsection{STI Risk}

To have confidence in the specifications that include STI risk, I must prove that the variable STI risk is not endogenous to sex workers' decisions that might be correlated with other relevant characteristics. For instance, it might be that sex workers' valuation of clients' risk is correlated with some client-specific effect such as wealth. Perhaps clients with high STI risk are more likely to be wealthy, and, since wealthier clients are more able to pay for transactional sex, an estimate of STI risk's effect on the price premium for unprotected sex would result in a positive relationship, however spurious this relationship might be.

To control for such possibilities, I control for clients' wealth, cleanliness, looks, and ethnicity. Results presented in Table 7.4 are robust to these controls. I also control for any sex worker-specific characteristics that do not change over time by running the sex worker fixed effects. I also control for sex workers' age, experience, years of education, literacy, tribe, marital status, and number of children. I also include day and month dummies to account for any demand effects that are day- or month-specific. Once again, results presented in Table 7.4 are robust to these controls. To capture the possibility 
that errors are likely correlated for a particular woman, I cluster standard errors at the sex worker level. All results report these sex worker-clustered standard errors.

Finally, I also run an instrumental variable estimation that uses the uncircumcised clients as an instrument for STI risk. This estimation allows me to test for endogeneity of my STI risk variable, thus providing greater confidence that the relationship between STI risk and the price premium for unprotected sex is identified. I exploit the fact that a sexual transaction with an uncircumcised men is external to the sex worker's choice. ${ }^{25}$ I also exploit the fact that uncircumcised men are more likely to get infected with HIV/AIDS, among other $\mathrm{STIs}^{26}$, in order to remove any endogenous variation in the STI risk variable by using uncircumcised clients as an instrument for STI risk. One might worry that the exclusion restriction might not hold because who is and is not circumcised might be related to ethnicity and other factors that could be related to prices paid. For one, I run a a simple linear regression expressing client characteristics as statistically significant predictors of circumcision and find that indeed being a Luo; Teso; and have handsome looks positively predicts circumcision status. But when I run these predictors in a linear regression with price, almost all become negative and not statistically significant at 10 percent. ${ }^{27}$ So although I find that some client characteristics are linked to circumcision status, these characteristics do not predict price.

Table 7.8 here.

Table 7.8 presents results from the two-stage least squares (2SLS) estimation using uncircumcised clients as an instrument for STI risk. The coefficient on STI risk is 246 Ksh (USD 3.5), but not statistically significant at 10 percent. After the IV estimateion, I

\footnotetext{
${ }^{25}$ Sex workers can decline a sexual transaction with an uncircumcised client, or avoid clients they know to be uncircumcised from previous sexual encounters but for an overwhelming majority of sex workers, the choice of having sex with an uncircumcised client is largely outside their control.

${ }^{26}$ Many studies show that uncircumcised men are relatively more likely to get infected with HIV/AIDS, genital herpes, syphilis, chancroid and other STIs. For further reading on this see for instance Bailey et al. (2007); Gray et al. (2007); Weiss et al. (2006); Auvert et al. (2005); Weiss et al. (2000); and Bongaarts et al. (1989).

${ }^{27}$ Results of these available upon request.
} 
conduct the Durbin-Wu-Hausman test for endogeneity to test for the endogeneity of my STI risk measure. Results from the test, presented in Table 7.9, show that at 10 percent level of significance, we fail to reject the null hypothesis that STI risk is exogenous.

Table 7.9 here.

\subsection{Pregnancy Risk}

Underlying my introduction of pregnancy risk as a novel source of the price premium for unprotected sex is that condoms prevent both STI and pregnancy. To convincingly show that a compensating differential for pregnancy risk is identified, it must find a channel that increases the chances of pregnancy, while not affecting the chances of STI transmission. Birth control certainly allows me to observe marginal increases in pregnancy risk while not affecting the probabilitiy of STI transmission. Even more robustly, what I would like is to run my main pregnancy risk specification, control for unprotected sex, risky clients, STI risk, and all other sex worker, client, and time controls, including of course the sex worker fixed effects specification, clustering standard errors at the sex worker level. I would then predict prices conditional on all of these observables; plot these predicted prices along my probability of pregnancy dimension, for sex workers with birth control and those without birth control. Ideally, I would observe predicted prices conditional on all the aforementioned, for sex workers without birth control, be higher than predicted prices for sex workers with birth control. Figure 5.2 presents results from just that.

The bars are average predicted prices from a sex worker fixed effects regression that includes controlling for all sex worker controls; client controls; time dummies; unprotected sex; and STI risk. Specifically, the red bars are average predicted prices only for sex workers without birth control, and thus non-negligible probabilities of pregnancy, depending on their menstrual cycle, while the blue bars are average predicted prices only for sex workers with birth control. This figure illustrates a robust price differential 
between prices received by sex workers without birth control relative to sex workers with birth control.

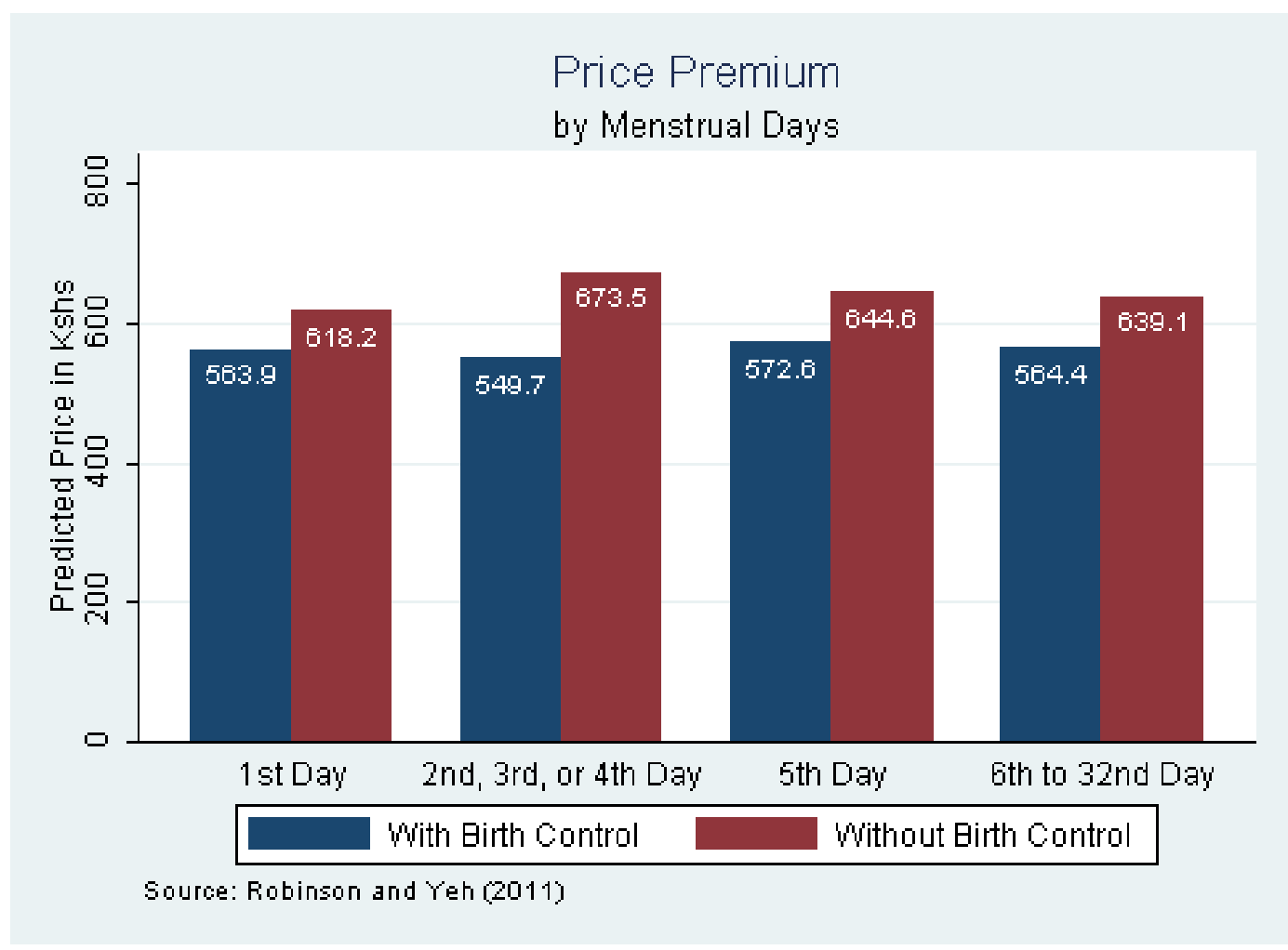

Figure 5: Conditional Predicted Price by Birth Control Across Menstrual Cycle.

I go even further, however, by running a placebo test on birth control. I run a sex worker fixed effects regression that includes all sex worker controls; client controls; time dummies; as well as unprotected sex. Most importantly, I include the interaction (No Condom $\times$ Probability of Pregnancy) which captures the chances of a sex worker getting pregnant. Once again, I cluster standard errors at the sex worker level and run this regression only for sex workers who are on birth control. If there exists no compensating differential for pregnancy risk, then the coefficient on this main pregnancy risk variable will not have any predictive power on price because we should not expect sex workers 
who are on birth control to worry about pregnancy risk. Table 7.10 presents the results from this estimation.

Table 7.10 here.

Although the coefficient of $1,727.8 \mathrm{Ksh}$ (USD 24.7) is sufficiently large, it is however not statistically significant at 10 percent. In short, this is further evidence that a compensating differential for pregnancy risk is a source of the price premium for unprotected sex. But to be even more robust, I also run my main pregnancy risk specification an instrumental variable approach using the direct probability of pregnancy as an instrument for pregnancy risk.

Table 7.11 here.

Table 7.11 presents results from this IV approach. Results show that there is still a price premium for pregnancy risk; however, this is not statistically significant at the 10 percent level. Using this same IV approach, however, we are able to test whether our main measure of pregnancy risk is endogenous. Table 7.12 presents results from testing the endogeneity of the pregnancy risk variable. Results from the test show that, at the 10 percent level of significance, we fail to reject the null hypothesis that pregnancy risk is exogenous.

Table 7.12 here.

Finally, another important identifying assumption is that the menstrual cycle, which reflects an exogenous measure of pregnancy risk, explains the price premium for pregnancy risk. To be true, an underlying assumption is that sex workers also understand and are aware of this pregnancy risk, i.e. they have knowledge about the Standard Days Method or other fertility awareness-based methods (University 2013). ${ }^{28}$ The confidence

\footnotetext{
${ }^{28}$ These methods involve the woman being aware and keeping track of her menstrual cycle in order to avoid having unprotected sex during her peak fertile days.
} 
that sex workers are aware of their respective chances of getting pregnant stem from two sources. First, recall that sex workers in the dataset have high HIV/AIDS knowledge. Table 7.3 presents that the average test score on HIV/AIDS knowledge (in a scale of 0-1) is 0.94. Second, and even more robust, I run a linear regression using this HIV/AIDS knowledge test score as a predictor of whether a sex worker uses birth control. The assumption here is that HIV/AIDS knowledge is strongly correlated with pregnancy risk knowledge. Table 7.13 presents results from this regression. Although the coefficient is not statistically significant at 10 percent, sex workers with higher HIV/AIDS knowledge are more likely to use birth control, providing suggestive evidence that sex workers are not uninformed about pregnancy risks.

Table 7.13 here.

Having said that, the single-most limitation of this paper is the availability of data that would allow us to better estimate the compensating differential for pregnancy risk. Better data on the specific sex worker-menstrual day mapping would allow us to find more precise estimates. However, this paper, given data constraints, constitutes not only the most rigorous attempt at exploring pregnancy risk as a source of the price premium for unprotected sex, but goes further by identifying it.

\section{Conclusion}

Using a rich dataset from Robinson and Yeh (2011) containing information on risky clients, clients' preferences for condom use, and pregnancy relevant variables, I identify and estimate the sources of the price premium for unprotected sex. I find that a compensating differential for STI risk and pregnancy risk are sources of the price premium for unprotected sex. Sex workers are risk averse to both STI and pregnancy because of the non-trivial costs of taking care of children for the latter and the costs of mitigating 
STI transmission for the former. I find that clients' disutility for condoms, the other competing theory, is not a source of the price premium for unprotected sex.

Identifying and estimating the sources of the price premium is important because the ultimate goal of public policy should be to reduce incentives of sex workers to supply unprotected sex and clients to demand unprotected sex. Because sex workers contribute to the transmission of HIV/AIDS and it requires billions of dollars to take care for vulnerable children such as HIV/AIDS orphans (Stover et al. 2007), understanding sex workers' fertility preferences and reducing their incentives to have unprotected sex will save resource-constraints governments in the developing world money that can be better targeted to intervene with sex workers and clients. Knowledge about the source of the price premium for unprotected sex is informative and prescriptive when determining how public health interventions should be targeted. Future work could possibly explore these potential avenues as well as look at whether sex workers respond to economic incentives to engage in safe sex. 


\section{References}

Arunachalam, R. and M. Shah (2013). Compensated for life: Sex work and disease risk. Journal of Human Resources 48(2), 345-369.

Auvert, B., D. Taljaard, E. Lagarde, J. Sobngwi-Tambekou, R. Sitta, and A. Puren (2005). Randomized, controlled intervention trial of male circumcision for reduction of hiv infection risk: the anrs 1265 trial. PLoS medicine 2(11), e298.

Bailey, R. C., S. Moses, C. B. Parker, K. Agot, I. Maclean, J. N. Krieger, C. F. Williams, R. T. Campbell, and J. O. Ndinya-Achola (2007). Male circumcision for hiv prevention in young men in kisumu, kenya: a randomised controlled trial. The Lancet 369(9562), 643-656.

Becker, G. S. (1993). A Treatise on the Family. Harvard university press.

Bongaarts, J., P. Reining, P. Way, and F. Conant (1989). The relationship between male circumcision and hiv infection in african populations. Aids 3(6), 373-378.

Davis, K. R. and S. C. Weller (1999). The effectiveness of condoms in reducing heterosexual transmission of hiv. Family planning perspectives, 272-279.

Dunson, D. B., D. D. Baird, A. Wilcox, and C. Weinberg (1999). Day-specific probabilities of clinical pregnancy based on two studies with imperfect measures of ovulation. Human Reproduction 14 (7), 1835-1839.

Edlund, L. and E. Korn (2002). A theory of prostitution. Journal of Political Economy 110(1), 181-214.

Freund, M. (1962). Interrelationships among the characteristics of human semen and factors affecting semen-specimen quality. Journal of Reproduction and Fertility 4(2), $143-159$.

Gertler, P., M. Shah, and S. M. Bertozzi (2005). Risky business: the market for unprotected commercial sex. Journal of Political Economy 113(3), 518-550.

Gray, R. H., G. Kigozi, D. Serwadda, F. Makumbi, S. Watya, F. Nalugoda, N. Kiwanuka, L. H. Moulton, M. A. Chaudhary, M. Z. Chen, et al. (2007). Male circumcision for hiv prevention in men in rakai, uganda: a randomised trial. The Lancet 369(9562), $657-666$.

Levitt, S. D. and S. A. Venkatesh (2007). An empirical analysis of street-level prostitution. Preliminary draft, September.

MacLeod, J. and R. Z. Gold (1953). The male factor in fertility and infertility. vi. semen quality and certain other factors in relation to ease of conception. Obstetrical E Gynecological Survey 8(4), 604-606. 
Ntumbanzondo, M., R. Dubrow, L. M. Niccolai, K. Mwandagalirwa, and M. Merson (2006). Unprotected intercourse for extra money among commercial sex workers in kinshasa, democratic republic of congo. AIDS care 18(7), 777-785.

Oster, E. (2005). Sexually transmitted infections, sexual behavior, and the hiv/aids epidemic. The Quarterly Journal of Economics 120(2), 467-515.

Poland, M., K. Moghissi, P. Giblin, J. Ager, and J. Olson (1985). Variation of semen measures within normal men. Fertility and sterility 44(3), 396-400.

Posner, R. A. (1992). Sex and reason. Harvard University Press.

Rao, V., I. Gupta, M. Lokshin, and S. Jana (2003). Sex workers and the cost of safe sex: the compensating differential for condom use among calcutta prostitutes. Journal of Development Economics 71(2), 585-603.

Robinson, J. and E. Yeh (2011). Transactional sex as a response to risk in western kenya. American Economic Journal: Applied Economics 3(1), 35-64.

Siow, A. (1998). Differntial fecundity, markets, and gender roles. Journal of Political Economy 106(2), 334-354.

Stover, J., L. Bollinger, N. Walker, and R. Monasch (2007). Resource needs to support orphans and vulnerable children in sub-saharan africa. Health policy and planning 22(1), $21-27$.

UNAIDS (2009, March). Unaids guidance note on hiv and sex work.

UNAIDS (2010). Unaids report on the global aids epidemic 2010.

University, G. (2013). Standard days method. Institute for Reproductive Health.

Weiss, H., S. Thomas, S. Munabi, and R. Hayes (2006). Male circumcision and risk of syphilis, chancroid, and genital herpes: a systematic review and meta-analysis. Sexually Transmitted Infections 82(2), 101-110.

Weiss, H. A., M. A. Quigley, and R. J. Hayes (2000). Male circumcision and risk of hiv infection in sub-saharan africa: a systematic review and meta-analysis. Aids 14(15), $2361-2370$.

Weitzman, L. J. and R. B. Dixon (1979). Child custody awards: Legal standards and empirical patterns for child custody, support and visitation after divorce. UCDL Rev. 12, 471.

Wilcox, A. J., D. B. Dunson, C. R. Weinberg, J. Trussell, and D. D. Baird (2001). Likelihood of conception with a single act of intercourse: providing benchmark rates for assessment of post-coital contraceptives. Contraception 63(4), 211-215. 
Wilcox, A. J., C. R. Weinberg, and D. D. Baird (1995). Timing of sexual intercourse in relation to ovulationeffects on the probability of conception, survival of the pregnancy, and sex of the baby. New England Journal of Medicine 333(23), 1517-1521. 


\section{Tables}

\subsection{Table 1: Sex Worker Information}

\begin{tabular}{|c|c|}
\hline \multicolumn{2}{|c|}{ Summary Statistics } \\
\hline Age & $\begin{array}{l}28.43 \\
(6.98)\end{array}$ \\
\hline Start Age & $\begin{array}{l}18.67 \\
(5.14)\end{array}$ \\
\hline Experience & $\begin{array}{c}9.84 \\
(6.07)\end{array}$ \\
\hline Years of Education & $\begin{array}{c}9.20 \\
(2.69)\end{array}$ \\
\hline Number of Biological Children & $\begin{array}{c}2.06 \\
(1.83)\end{array}$ \\
\hline Marital Status & \\
\hline Never Married & $\begin{array}{c}0.44 \\
(0.50)\end{array}$ \\
\hline Widowed & $\begin{array}{c}0.23 \\
(0.42)\end{array}$ \\
\hline Divorced & $\begin{array}{c}0.20 \\
(0.40)\end{array}$ \\
\hline Cohabitating & $\begin{array}{c}0.13 \\
(0.33)\end{array}$ \\
\hline Can Read Kiswahili & $\begin{array}{c}0.95 \\
(0.21)\end{array}$ \\
\hline Can Write Kiswahili & $\begin{array}{c}0.88 \\
(0.33)\end{array}$ \\
\hline Tribe & \\
\hline Luo & $\begin{array}{c}0.51 \\
(0.50)\end{array}$ \\
\hline Luhya & $\begin{array}{c}0.39 \\
(0.49)\end{array}$ \\
\hline HIV Knowledge Test Score (0-1 Scale) & $\begin{array}{c}0.94 \\
(0.06)\end{array}$ \\
\hline Vaginal Sex & $\begin{array}{c}0.94 \\
(0.10)\end{array}$ \\
\hline Income from Sex Work per Day (Ksh) & $\begin{array}{c}850.71 \\
(460.99)\end{array}$ \\
\hline Hours in Sex Work per Day & $\begin{array}{c}7.35 \\
(2.40)\end{array}$ \\
\hline Income from Other Work per Day (Ksh) & $\begin{array}{c}106.08 \\
(120.14)\end{array}$ \\
\hline Hours in Other Work per Day & $\begin{array}{c}7.73 \\
(39.33)\end{array}$ \\
\hline Hourly Wage from Sex Work (Ksh) & $\begin{array}{l}151.77 \\
(92.24)\end{array}$ \\
\hline Hourly Wage from Other Work (Ksh) & $\begin{array}{c}41.07 \\
(38.54)\end{array}$ \\
\hline Observations & 192 \\
\hline
\end{tabular}

Note: Means are presented with standard deviations in parentheses. 


\subsection{Table 2: Client Information}

\begin{tabular}{|c|c|}
\hline \multicolumn{2}{|c|}{ Summary Statistics } \\
\hline Disutility for Condoms & $\begin{array}{c}0.45 \\
(0.45)\end{array}$ \\
\hline Disutility for Condoms for Unrisky Clients & $\begin{array}{c}0.21 \\
(0.38)\end{array}$ \\
\hline Risky Clients & $\begin{array}{c}0.46 \\
(0.46)\end{array}$ \\
\hline Uncircumcised Clients & $\begin{array}{c}0.25 \\
(0.40)\end{array}$ \\
\hline Poor Clients & $\begin{array}{c}0.09 \\
(0.26)\end{array}$ \\
\hline Clean Clients & $\begin{array}{c}0.62 \\
(0.44)\end{array}$ \\
\hline Handsome Clients & $\begin{array}{c}0.54 \\
(0.46)\end{array}$ \\
\hline Tribe & \\
\hline Luhya & $\begin{array}{c}0.25 \\
(0.40)\end{array}$ \\
\hline Luo & $\begin{array}{c}0.24 \\
(0.39)\end{array}$ \\
\hline Kikuyu & $\begin{array}{c}0.14 \\
(0.32)\end{array}$ \\
\hline Teso & $\begin{array}{c}0.09 \\
(0.26)\end{array}$ \\
\hline Kalenjin & $\begin{array}{c}0.06 \\
(0.22)\end{array}$ \\
\hline Somali & $\begin{array}{c}0.06 \\
(0.23)\end{array}$ \\
\hline Akamba & $\begin{array}{c}0.05 \\
(0.21)\end{array}$ \\
\hline Ugandan & $\begin{array}{c}0.04 \\
(0.17)\end{array}$ \\
\hline Occupation & \\
\hline Government & $\begin{array}{c}0.27 \\
(0.41)\end{array}$ \\
\hline Truck Driver & $\begin{array}{c}0.19 \\
(0.36)\end{array}$ \\
\hline Business & $\begin{array}{c}0.19 \\
(0.36)\end{array}$ \\
\hline Hotel & $\begin{array}{c}0.10 \\
(0.27)\end{array}$ \\
\hline Shop & $\begin{array}{c}0.09 \\
(0.26)\end{array}$ \\
\hline Boda Boda (Bike Taxi) Driver & $\begin{array}{c}0.08 \\
(0.25)\end{array}$ \\
\hline Bar & $\begin{array}{c}0.05 \\
(0.20)\end{array}$ \\
\hline Other & $\begin{array}{c}0.03 \\
(0.16)\end{array}$ \\
\hline Observations & 3,656 \\
\hline
\end{tabular}

Note: Means are presented with standard deviations in parentheses. 


\subsection{Table 3: Sexual Transactions}

Summary Statistics

\begin{tabular}{lc}
\hline \hline Price for Sexual Transaction (Ksh) & 509.51 \\
Unprotected Vaginal Sex & $(286.41)$ \\
& 0.08 \\
STI & $(0.14)$ \\
& 0.03 \\
STI Risk & $(0.07)$ \\
Birth Control & 0.03 \\
& $(0.10)$ \\
Menstruation Today & 0.60 \\
Menstruation Yesterday & $(0.49)$ \\
Pregnancy Risk & 0.08 \\
\hline
\end{tabular}

Note: Means are presented with standard deviations in parentheses. 


\subsection{Table 4: STI Risk as a Source of the Price Premium for Unpro- tected Sex}

STI Risk as a Source of the Price Premium for Unprotected Sex

\begin{tabular}{|c|c|c|c|c|}
\hline & (1) & $(2)$ & $(3)$ & $(4)$ \\
\hline & Ksh & Ksh & Ksh & Ksh \\
\hline \multirow[t]{2}{*}{ No Condom } & & & -4.263 & 1.325 \\
\hline & & & $(31.17)$ & $(30.12)$ \\
\hline \multirow[t]{2}{*}{ Risky Client } & & & -10.95 & -3.104 \\
\hline & & & $(26.02)$ & $(27.16)$ \\
\hline \multirow[t]{2}{*}{ No Condom*Risky Client } & $128.9^{*}$ & $142.7^{* *}$ & $138.5^{*}$ & $143.4^{*}$ \\
\hline & $(72.20)$ & $(68.87)$ & $(74.98)$ & $(77.80)$ \\
\hline Sex Worker Controls & No & Yes & No & Yes \\
\hline Client Controls & No & Yes & No & Yes \\
\hline Time Dummies & Yes & Yes & Yes & Yes \\
\hline Fixed Effects & Yes & Yes & Yes & Yes \\
\hline \multirow[t]{2}{*}{ Constant } & $574.8^{* * *}$ & $609.8^{* * *}$ & $578.0^{* * *}$ & $609.8^{* * *}$ \\
\hline & $(75.16)$ & $(78.59)$ & $(75.98)$ & $(79.02)$ \\
\hline $\mathrm{Kshs}^{e}$ & 588.1 & 590 & 588.1 & 590 \\
\hline Sexual Transactions & 2506 & 2378 & 2506 & 2378 \\
\hline R-Squared & 0.00915 & 0.0203 & 0.00926 & 0.0203 \\
\hline F Statistic & 1.593 & 4.534 & 1.523 & 4.258 \\
\hline
\end{tabular}

Notes:
a. Standard errors clustered at the sex worker level in parentheses.
b. *** $1 \%$ level of confidence.
c. ${ }^{* *} 5 \%$ level of confidence.
d. $* 10 \%$ level of confidence.
e. Mean of Ksh. 


\subsection{Table 5: Pregnancy Risk as a Source of the Price Premium for Unprotected Sex}

\begin{tabular}{|c|c|c|c|c|}
\hline & $(1)$ & $(2)$ & $(3)$ & $(4)$ \\
\hline & Ksh & Ksh & Ksh & Ksh \\
\hline \multirow[t]{2}{*}{ No Condom } & & & 32.02 & 4.063 \\
\hline & & & $(37.66)$ & $(26.32)$ \\
\hline \multirow[t]{2}{*}{ Probability of Pregnancy } & & & 319.2 & $514.1^{* *}$ \\
\hline & & & $(267.4)$ & $(230.1)$ \\
\hline \multirow[t]{2}{*}{ Probability of Pregnancy*No Birth Control } & & & -368.1 & $-992.9^{* *}$ \\
\hline & & & $(447.3)$ & $(413.4)$ \\
\hline \multirow[t]{2}{*}{ No Condom*Probability of Pregnancy*No Birth Control } & $714.6^{*}$ & $708.8^{* *}$ & 499.6 & $716.0^{* *}$ \\
\hline & $(363.5)$ & $(292.3)$ & $(433.2)$ & $(349.6)$ \\
\hline Sex Worker Controls & No & Yes & No & Yes \\
\hline Client Controls & No & Yes & No & Yes \\
\hline Time Dummies & Yes & Yes & Yes & Yes \\
\hline Fixed Effects & Yes & Yes & Yes & Yes \\
\hline \multirow[t]{2}{*}{ Constant } & $536.5^{* * *}$ & $654.3^{* * *}$ & $493.2^{* * *}$ & $641.2^{* * *}$ \\
\hline & $(53.38)$ & $(151.1)$ & $(63.89)$ & $(154.4)$ \\
\hline $\mathrm{Kshs}^{e}$ & 553.7 & 536.8 & 553.7 & 536.8 \\
\hline Sexual Transactions & 6361 & 3493 & 6361 & 3493 \\
\hline R-Squared & 0.00282 & 0.0133 & 0.00345 & 0.0148 \\
\hline F Statistic & 1.301 & 1.902 & 1.449 & 2.068 \\
\hline
\end{tabular}

Notes:
a. Standard errors clustered at the sex worker level in parentheses.
b. *** $1 \%$ level of confidence.
c. ** $5 \%$ level of confidence.
d. $* 10 \%$ level of confidence.
e. Mean of Ksh. 


\subsection{Table 6: Clients' Disutility for Condoms as a Source of the Price Premium for Unprotected Sex}

Clients' Disutility for Condoms as a Source of the Price Premium for Unprotected Sex

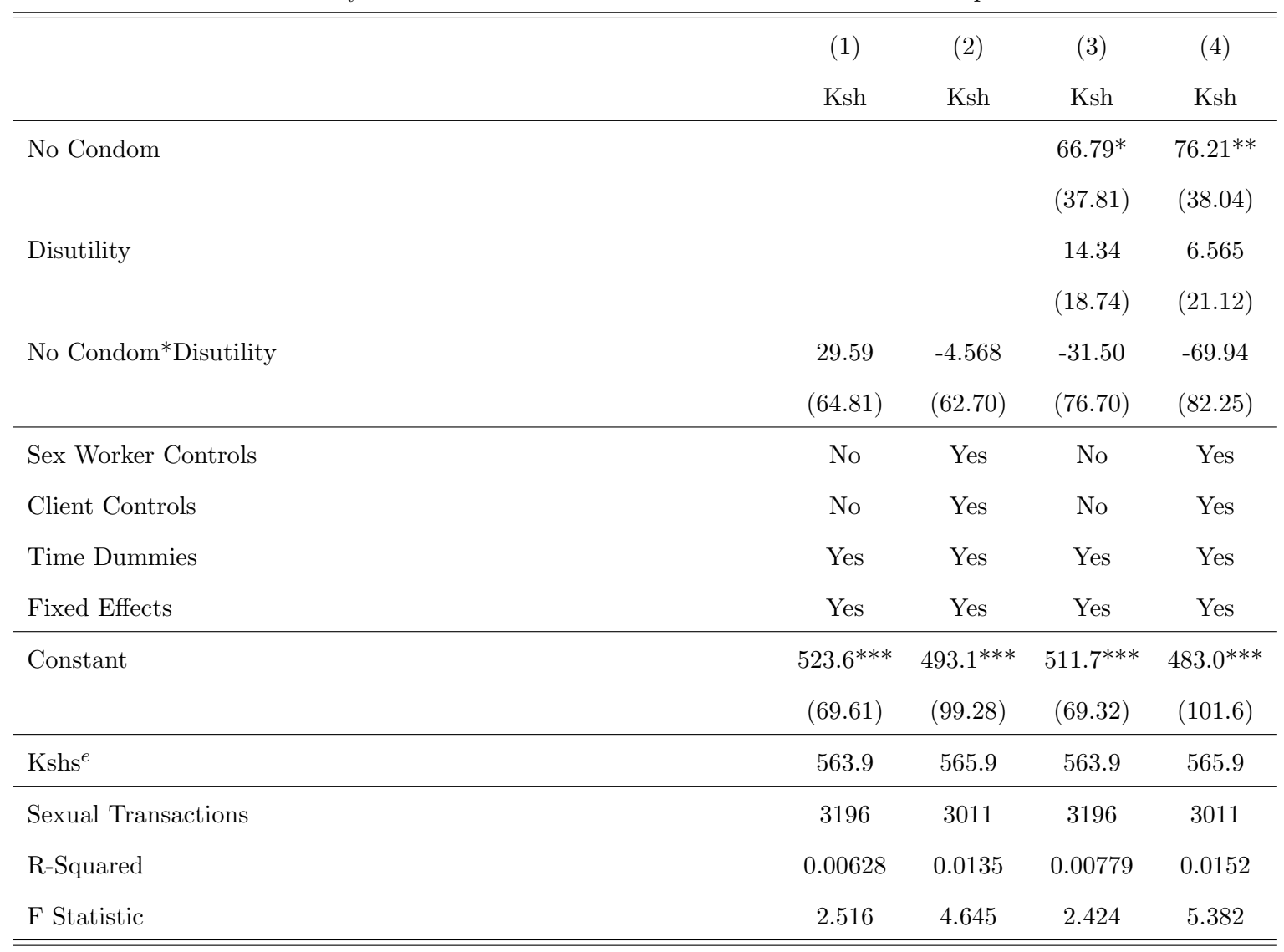

Notes:

a. Standard errors clustered at the sex worker level in parentheses.

b. $* * * 1 \%$ level of confidence.

c. ${ }^{* *} 5 \%$ level of confidence.

d. * $10 \%$ level of confidence.

e. Mean of Ksh. 


\subsection{Table 7: STI Risk and Pregnancy Risk as Sources of the Price Premium for Unprotected Sex}

STI Risk and Pregnancy Risk as Sources of the Price Premium for Unprotected Sex

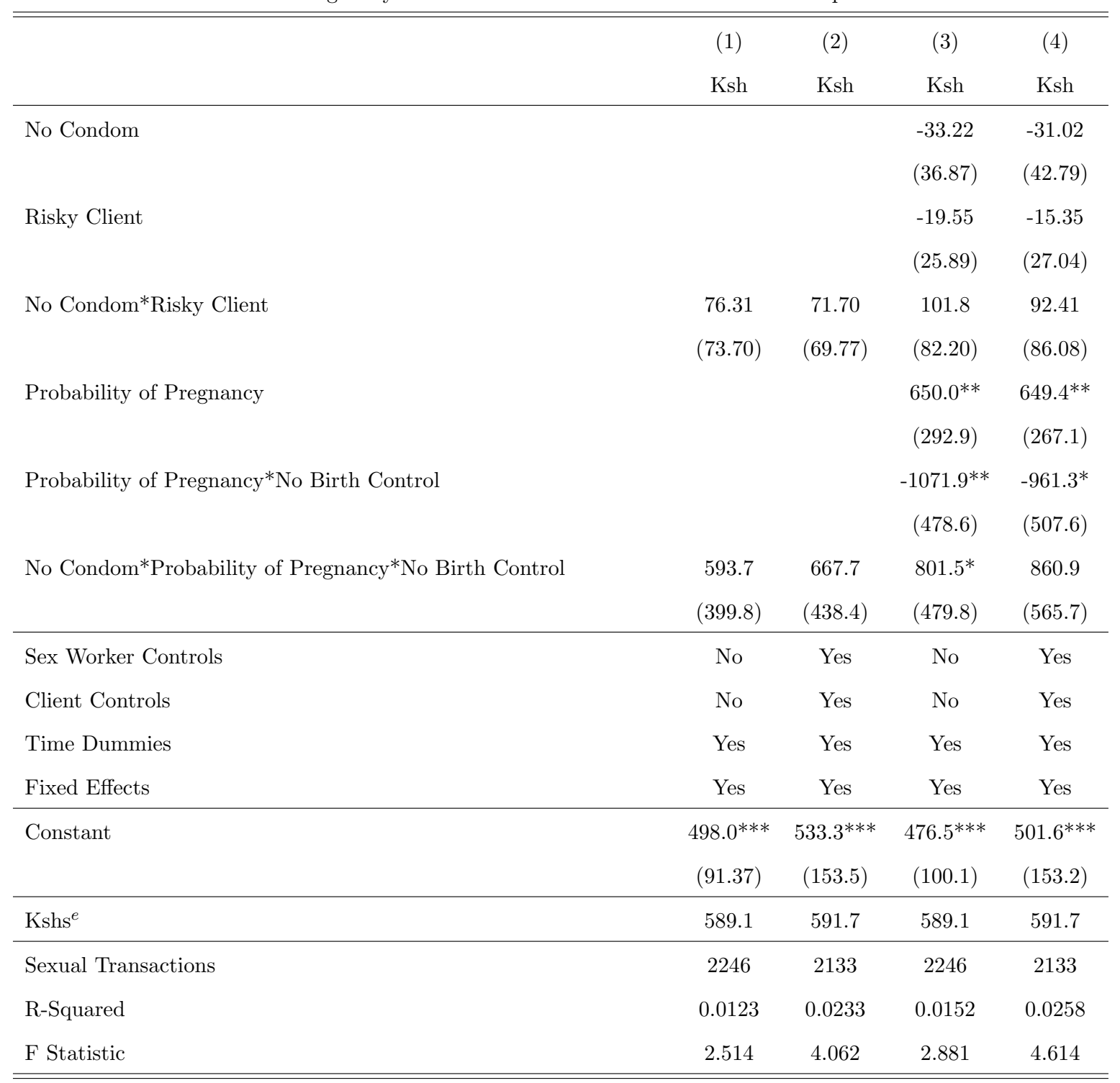

Notes:

a. Standard errors clustered at the sex worker level in parentheses.

b. $* * * 1 \%$ level of confidence.

c. ${ }^{* *} 5 \%$ level of confidence.

d. $* 10 \%$ level of confidence.

e. Mean of Ksh. 
7.8 Table 8: Instrumental Variable with Uncircumcised Clients as Instrument for STI Risk

IV: Uncircumcised Client as Instrument for STI Risk

\begin{tabular}{lc}
\hline \hline & $(1)$ \\
& Ksh \\
\hline No Condom*Risky Client & 245.7 \\
\hline Sex Worker Controls & $(965.7)$ \\
Client Controls & Yes \\
Time Dummies & Yes \\
\hline Constant & Yes \\
\hline Kshs ${ }^{e}$ & $923.8^{* * *}$ \\
\hline Sexual Transactions & $(266.2)$ \\
Adjusted R-Squared & 594.6 \\
Chi-Squared & 2331 \\
\hline \hline
\end{tabular}

Notes:

a. Standard errors clustered at the sex worker level in parentheses.

b. *** $1 \%$ level of confidence.

c. ${ }^{* *} 5 \%$ level of confidence.

d. * $10 \%$ level of confidence.

e. Mean of Ksh. 


\subsection{Table 9: Is STI Risk Endogenous?}

Null Hypothesis: STI Risk is Exogenous

\begin{tabular}{lr}
\hline \hline & STI Risk \\
\hline Robust Chi2 (1) & 0.126783 \\
& $(0.7218)$ \\
Robust F $(1,2316)$ & 0.125192 \\
& $(0.7235)$ \\
\hline Note: & \\
a. P-values in parentheses. & \\
b. Uncircumcised clients used as instrument, with CSW, Client and Time Controls. \\
\hline
\end{tabular}




\subsection{Table 10: Placebo Test}

Placebo Test: Pregnancy Risk for Sex Workers on Birth Control

\begin{tabular}{lc}
\hline \hline & $(1)$ \\
& Ksh \\
\hline No Condom*Probability of Pregnancy & 1727.77 \\
& $(1198.1)$ \\
\hline Sex Worker Controls & Yes \\
Client Controls & Yes \\
Time Dummies & Yes \\
Fixed Effects & Yes \\
\hline Constant & $546.0 * * *$ \\
& $(96.3)$ \\
\hline Sexual Transactions & 2236 \\
R-Squared & 0.0039 \\
\hline
\end{tabular}

Notes:

a. Standard errors clustered at the sex worker level in parentheses.

b. *** $1 \%$ level of confidence.

c. ${ }^{* *} 5 \%$ level of confidence.

d. * $10 \%$ level of confidence. 


\subsection{Table 11: Instrumental Variable with Probability of Pregnancy}

as Instrument for Pregnancy Risk

IV: Probability of Pregnancy as Instrument for Pregnancy Risk

\begin{tabular}{lc}
\hline \hline & $(1)$ \\
& Ksh \\
\hline No Condom*Probability of Pregnancy*No Birth Control & 2204.5 \\
& $(11109.6)$ \\
\hline Sex Worker Controls & Yes \\
Client Controls & Yes \\
Time Dummies & Yes \\
\hline Constant & 582.2 \\
& $(390.7)$ \\
\hline Kshe & 536.8 \\
\hline Sexual Transactions & 3493 \\
Adjusted R-Squared & 0.100 \\
Chi-Squared & 117.0 \\
\hline \hline
\end{tabular}

Notes:

a. Standard errors clustered at the sex worker level in parentheses.

b. ${ }^{* * *} 1 \%$ level of confidence.

c. ${ }^{* *} 5 \%$ level of confidence.

d. * $10 \%$ level of confidence.

e. Mean of Ksh. 


\subsection{Table 12: Is Pregnancy Risk Endogenous?}

Is Pregnancy Risk Endogenous?

Null Hypothesis: Pregnancy Risk is Exogenous

\begin{tabular}{lc}
\hline \hline & Pregnancy Risk \\
\hline Robust Chi2 (1) & 0.514959 \\
& $(0.4730)$ \\
Robust F $(1,3525)$ & 0.513386 \\
& $(0.4737)$ \\
\hline \hline Note: & \\
a. P-values in parentheses. & \\
b. Probability of pregnancy used as instrument, with sex worker, client and time controls. & \\
\hline
\end{tabular}




\subsection{Table 13: Pregnancy Knowledge}

Are Sex Workers Knowledgeable About Pregnancy?

(1)

Birth Control

\begin{tabular}{lc}
\hline HIV Knowledge $^{e}$ & 0.529 \\
& $(0.986)$ \\
\hline Sex Worker Controls & Yes \\
Client Controls & Yes \\
Time Dummies & Yes \\
\hline Constant & -0.723 \\
& $(0.938)$ \\
\hline Sexual Transactions & 3775 \\
R-Squared & 0.277 \\
F-Statistic & 3.946 \\
\hline \hline
\end{tabular}

Notes:

a. Standard errors clustered at the sex worker level in parentheses.

b. *** $1 \%$ level of confidence.

c. ${ }^{* *} 5 \%$ level of confidence.

d. * $10 \%$ level of confidence.

e. HIV Knowledge Test Score (0-1 Scale). 


\section{A Appendix}

\section{B Figures}

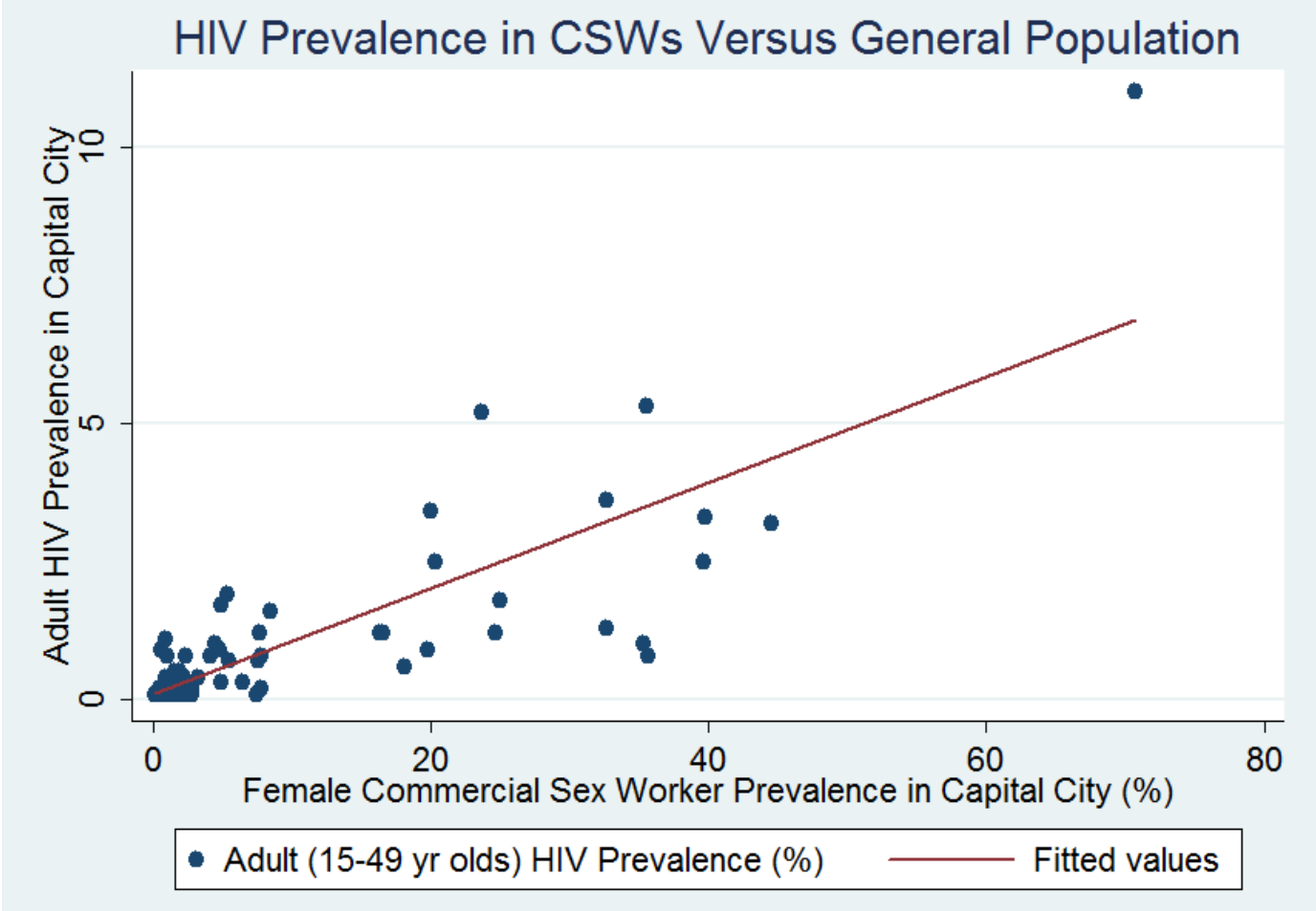




\section{B.1 Proof}

\section{B.2 Of the Proposition}

Proof. Let $P_{1}-P_{2}>0$ so that the price premium for unprotected sex exists. This implies that $G C_{g}+S C_{s}>0$.

Let $S C_{s}=0$.

Now, if $P_{1}-P_{2}>0$ and $S C_{s}=0$, then it is trivially shown that $G C_{g}>0$ automatically, but it can also be shown deductively because the product of two numbers can be positive only if both are positive or both are negative. Since the lower bound on a probability is zero then $G$ can at minimum only be zero. And since we know that $G C_{g}>0$ and it cannot be $<0$ then it must be positive. And since $G$ is positive, then so too must $C_{g}$ be positive. 